\title{
PESQUISA EM EDUCAÇÃO AMBIENTAL E POLÍTICAS PÚBLICAS: APONTAMENTOS E MEMÓRIA DE UM PROCESSO
}

\author{
Luiz Carlos Santana ${ }^{1}$
}

Resumo: O presente artigo busca fazer um registro sobre o movimento da reflexão empreendida pelos pesquisadores participantes do Grupo de Discussão de Pesquisas (GDP) sobre Pesquisa em Educação Ambiental e Políticas Públicas, ocorrido durante o VII EPEA (Julho de 2013). Registro, memória e perspectivas de pesquisa. Isto é feito a partir dos 21 trabalhos inscritos no GDP, que foram discutidos a partir da apresentação dos pesquisadores ou pelos excertos produzidos pelo coordenador e discutidos nos grupos de trabalho. A riqueza da discussão dos trabalhos foi constatada pela variedade dos temas tratados, dos objetivos propostos e das consequentes questões de pesquisa, bem como dos procedimentos teórico-metodológicos usados. Dois focos serviram de base para a discussão: os entendimentos de educação ambiental e os entendimentos de políticas públicas presentes nos trabalhos. Além da reflexão empreendida o artigo ressalta as perspectivas temáticas indicadas pelos pesquisadores participantes do GDP.

Palavras-chave: Pesquisa em Educação Ambiental. Políticas Públicas. Educação Ambiental.

\section{RESEARCH IN ENVIRONMENTAL EDUCATION AND PUBLIC POLICY: NOTES AND MEMORY OF A PROCESS}

Abstract: This paper aims to make a record about the movement of the reflection undertaken by the researchers participating in the Discussion Group Research (GDP) about Research in Environmental Education and Public Policy, occurred during the VII EPEA (July 2013). Registry, memory and research perspectives. This is done from the 21 works submitted in GDP, which were discussed from the presentation of the researchers or by the extracts produced by the coordinator and discussed in the working groups. The richness of the discussion of the works was seen by the variety of topics addressed, the proposed objectives and consequent research questions, as well as the theoretical and methodological procedures used. Two focuses formed the basis for discussion: the understandings of environmental education and understandings of public policies, observed in the works. Besides the reflection undertaken, this article highlights the thematic perspectives indicated by the participating researchers GDP.

Keywords: Research in Environmental Education. Public Policy. Environmental Education.

\footnotetext{
${ }^{1}$ Professor Assistente Doutor II do Instituto de Biociências, UNESP - Univ Estadual Paulista, Rio Claro, Departamento de Educação, Programa de Pós-graduação em Educação. luizcs@ @rc.unesp.br
} 


\section{INVESTIGACIÓN EN EDUCACIÓN AMBIENTAL Y POLÍTICAS PÚBLICAS: APUNTES Y LA MEMORIA DE UN PROCESO}

Resumen: Este artículo pretende hacer un registro sobre el movimiento de la reflexión llevada a cabo por los investigadores que participan en el Grupo de Discusión en Pesquisa (GDP) acerca de la Investigación en Educación Ambiental y Políticas Públicas, ocurrido durante el EPEA VII (julio de 2013). Registro, memoria y perspectivas de investigación. Esto se hace desde los 21 trabajos inscritos en el GDP, que fueron discutidos a partir de la presentación de los investigadores o de los extractos producidos por el coordinador y discutidos en los grupos de trabajo. La riqueza de la discusión de los trabajos fue vista por la variedad de temas tratados, los objetivos propuestos y las preguntas de investigación consiguientes, así como los procedimientos teóricos y metodológicos utilizados. Dos focos fueron la base para el debate: las concepciones de la educación ambiental y la comprensión de las políticas públicas observadas en los estudios. Además de la reflexión emprendida, este artículo pone de relieve las perspectivas temáticas señaladas por los investigadores participantes del GDP.

Palabras clave: Pesquisa en Educación Ambiental. Políticas Públicas. Educación Ambiental

\section{Introdução}

As políticas públicas, enquanto campo de conhecimento e de investigação, ressurgem, nas últimas décadas, como tema importante de discussão e reflexão, estabelecendo nexos entre diferentes disciplinas, tais como a economia, ciência política, sociologia, antropologia, geografia, planejamento, gestão e ciências sociais aplicadas (SOUZA, 2007, p.69). As pesquisas científicas sobre esta temática ganham fôlego, nas diversas áreas de conhecimento, a partir da década de 80 do século XX (GELINSKI; SEIBEL, 2008AS; MARQUES; FARIA, 2013).

No processo de consolidação da área de investigação sobre Educação Ambiental, o tema das políticas públicas tem, também, marcado presença e vai ganhando espaço, principalmente a partir do movimento de institucionalização das políticas públicas de educação ambiental na década de 90 (LAYRARGUES, 2002; LIMA, 2011a, 2011b; SORRENTINO; TRAJBER, 2007; TAMAIO, 2008).

O EPEA, além do GT 22 (ANPEd) e ANPPAS, tem sido reconhecido por diferentes pesquisadores (KAWASAKI et al., 2006, 2009; CAVALARI; SANTANA; CARVALHO, 2006; CARVALHO; SCHMIDT, 2008; CARVALHO; FARIAS, 2011; LIMA, 2011b; RINCK; MEGID NETO, 2009; JUNTA; SANTANA, 2011) como espaço privilegiado de discussão das pesquisas produzidas sobre educação ambiental, contribuindo, sobremaneira, para o processo de consolidação da área de pesquisa relativa ao tema no Brasil.

A primeira versão do EPEA ocorreu no campus da UNESP de Rio Claro, em julho de 2001, e, no mesmo mês de 2013 foi realizada a sétima versão do evento de pesquisa, no mesmo campus universitário. Os GDPs (Grupos de Discussão de Pesquisa) constituídos no âmbito do III EPEA, realizado no campus da USP de Ribeirão Preto, em 2005, têm proporcionado oportunidade ímpar de discussão sobre a produção de pesquisa na área de educação ambiental, contemplando eixos temáticos variados e 
consonantes com as pesquisas em desenvolvimento. Pesquisa em Educação Ambiental e Políticas Públicas passou a constituir um tema de GDP no V EPEA, realizado no campus da UFSCar, em São Carlos, em 2009 (GUIMARÃES; OLABARRIAGA; TONSO, 2009).

No V EPEA, dos 90 trabalhos aceitos para apresentação, 20 deles (23\% do total) foram apresentados no GDP de Pesquisa em Educação Ambiental e Políticas Públicas. No VI EPEA, realizado no campus da USP de Ribeirão Preto, em 2011, dos 85 trabalhos de pesquisa sobre Educação Ambiental apresentados, 11 deles $(12,94 \%)$ foram efetivamente inscritos e apresentados nesse GDP (FERRARO, 2012, p. 136). No VII EPEA, realizado em 2013, esse número voltou a subir, ou seja, foram inscritos 21 trabalhos para apresentação no GDP. Contudo, uma vez que o total de trabalhos aceitos para a pauta do evento foi também maior, ou seja, 104, a porcentagem referente aos trabalhos inscritos no GDP foi de 20,19\%, portanto um percentual menor que o dos trabalhos apresentados no GDP de Pesquisa em Educação Ambiental e Políticas Públicas durante o V EPEA, realizado em 2009. Apesar disso, o GDP, em razão dos trabalhos apresentados, tem dado mostras da vitalidade e da atualidade das questões refletidas em seu interior.

As discussões ocorridas no âmbito do GDP de Pesquisa em Educação Ambiental e Políticas Públicas, durante o VII EPEA, estiveram circunscritas aos aspectos próprios e diretamente vinculados à natureza do Grupo, ou seja, discussão de pesquisas produzidas sobre o tema e encaminhadas para o evento, procurando, a partir destas, explorar as principais tendências percebidas. Tais tendências poderiam ser notadas não apenas por meio dos subtemas tratados, como também dos objetivos propostos, das questões de pesquisas, dos procedimentos de investigação e dos suportes teóricometodológicos usados.

\section{Objetivo}

A intenção principal deste artigo é indicar o movimento de reflexão sobre as pesquisas a respeito de Educação Ambiental e Políticas Públicas discutidas durante o VII EPEA, registrando momentos importantes da discussão empreendida, bem como as perspectivas delineadas. Portanto, registro, memória e perspectivas. O artigo visa fornecer aos pesquisadores o registro de uma discussão sobre o tema, de modo que, enquanto registro e memória, possa contribuir para avançar e, também, para consolidar a temática no âmbito do GDP ou contribuir para a investigação de outros pesquisadores interessados. Objetivamos, aqui, mais o registro e memória do que respostas definitivas às questões discutidas pelos pesquisadores participantes do Grupo. Mesmo porque respostas definitivas inviabilizam qualquer tipo de pesquisa.

\section{Discussão temática}

A discussão no GDP teve início com a apresentação, pelos próprios pesquisadores presentes, dos principais aspectos tratados nos textos enviados para o evento. Dos 42 pesquisadores inscritos para participação no GDP, 25 participaram efetivamente no primeiro dia e 16 no segundo. Como já referido, 21 trabalhos foram inscritos nesse Grupo.

Os textos apresentados para discussão no GDP, em sua maioria, resultaram de trabalhos de pesquisa realizados tanto no âmbito de mestrado (como exemplo: Tr0138, 
Tr0160) quanto de doutorado (exemplo: Tr0044, Tr0071 e Tr0112). Outros foram apresentados no formato de ensaio teórico, como o caso do Tr0027, Tr0108-1, Tr0210-1 e Tr0210-2. A riqueza da discussão feita no GDP pode ser constatada pela variedade dos temas tratados, dos objetivos propostos e das consequentes questões de pesquisas, bem como dos procedimentos teórico-metodológicos usados.

A seguir, trazemos dois quadros que nos permitem ter uma noção sobre os temas e os objetivos dos trabalhos que, neste caso, muitas vezes explicitam também a problemática investigada. $^{2}$

\begin{tabular}{|c|c|c|}
\hline & ID. & TEMA \\
\hline 01 & $0027-1$ & $\begin{array}{l}\text { A representação dos princípios ambientais da informação e participação no âmbito da } \\
\text { Educação Ambiental. }\end{array}$ \\
\hline 02 & 0030-1 & A necessidade iminente do controle social no licenciamento ambiental. \\
\hline 03 & 0044-1 & $\begin{array}{l}\text { Remando contra a maré: o desafio da Educação ambiental crítica no licenciamento } \\
\text { ambiental. }\end{array}$ \\
\hline 04 & 0063-1 & $\begin{array}{l}\text { Análise crítica do programa de Educação Ambiental e agricultura familiar do Ministério do } \\
\text { Meio Ambiente. }\end{array}$ \\
\hline 05 & $0067-1$ & $\begin{array}{l}\text { Sustentabilidade e acessibilidade: um estudo sobre a Pontifícia Universidade Católica do } \\
\text { Rio Grande do Sul. }\end{array}$ \\
\hline 06 & 0069-1 & $\begin{array}{l}\text { A Agenda } 21 \text { escolar no estado de São Paulo: semelhanças e diferenças nas políticas } \\
\text { públicas de educação ambiental. }\end{array}$ \\
\hline 07 & $0071-1$ & $\begin{array}{l}\text { Uma análise dos projetos de Educação Ambiental no licenciamento off-shore de petróleo } \\
\text { da bacia de Campos. }\end{array}$ \\
\hline 08 & 0073-1 & $\begin{array}{l}\text { O programa agronegócio na escola: um estudo de caso sobre a Educação Ambiental } \\
\text { empresarial nas escolas públicas brasileiras. }\end{array}$ \\
\hline 09 & $0078-1$ & $\begin{array}{l}\text { Educação ambiental no licenciamento de petróleo e gás: um estudo sobre a implementação } \\
\text { de projetos voltados para pescadores artesanais do Recôncavo Baiano }\end{array}$ \\
\hline 10 & $0087-1$ & $\begin{array}{l}\text { Educação ambiental na extensão rural pública: uma análise dos princípios da política } \\
\text { nacional de assistência técnica e extensão rural. }\end{array}$ \\
\hline 11 & 0099-1 & $\begin{array}{l}\text { Percepção ambiental em relação à área verde da bacia hidrográfica do córrego da água } \\
\text { quente (São Carlos, SP) como subsídio para a educação ambiental. }\end{array}$ \\
\hline 12 & 0108-1 & $\begin{array}{l}\text { Os limites e possibilidades da educação ambiental no licenciamento: elementos pra o } \\
\text { debate. }\end{array}$ \\
\hline 13 & 0112-1 & $\begin{array}{l}\text { Para além dos discursos heroicos: um olhar sobre os debates ocorridos no contexto da } \\
\text { Rio+ } 20 \text {. }\end{array}$ \\
\hline 14 & 0126-1 & $\begin{array}{l}\text { Tendências das dissertações e teses sobre educação ambiental em áreas protegidas no } \\
\text { Brasil. }\end{array}$ \\
\hline 15 & 0138-1 & $\begin{array}{l}\text { Análise de uma política pública de educação ambiental: "comissão de meio ambiente e } \\
\text { qualidade de vida na escola-com-vida". }\end{array}$ \\
\hline 16 & 0160-1 & $\begin{array}{l}\text { A socialização da política em conselhos: um estudo de caso no Grupo Interdisciplinar de } \\
\text { Educação Ambiental (GIEA/RJ). }\end{array}$ \\
\hline 17 & 0186-1 & $\begin{array}{l}\text { O preconceito e a desinformação como obstáculos à transformação social: a educação } \\
\text { ambiental política como ferramenta de resgate da cidadania das mulheres na atividade } \\
\text { pesqueira. }\end{array}$ \\
\hline 18 & 0187-1 & $\begin{array}{l}\text { "O coletivo jovem de meio ambiente: uma contribuição à política governamental de } \\
\text { escolas sustentáveis dos ministérios da Educação e do Meio Ambiente". }\end{array}$ \\
\hline 19 & 0197-1 & $\begin{array}{l}\text { O tema "meio ambiente" nas diretrizes e parâmetros curriculares nacionais do Ensino } \\
\text { Médio". }\end{array}$ \\
\hline
\end{tabular}

\footnotetext{
${ }^{2}$ Os quadros foram montados, tendo como referência excertos feitos pelo coordenador da discussão no grupo, a partir da leitura dos trabalhos inscritos para apresentação no GDP de Pesquisa em Educação Ambiental e Políticas Públicas.
} 


\begin{tabular}{|l|l|l|}
\hline 20 & $0210-1$ & $\begin{array}{l}\text { Educação ambiental no Licenciamento de Atividades de Produção e Escoamento de Óleo e } \\
\text { Gás: as disputas de ideias e suas influências nos processos educativos. }\end{array}$ \\
\hline 21 & $0210-2$ & $\begin{array}{l}\text { Liberalismo e "terceira via": a educação ambiental como meio de sociabilização da classe } \\
\text { dominante. }\end{array}$ \\
\hline
\end{tabular}

QUADRO I - Temas dos trabalhos apresentados no GDP de Pesquisa em Educação Ambiental e Políticas Públicas - VII EPEA (2013)

Fonte: Trabalhos apresentados no GDP Pesquisa em Educação Ambiental e Políticas Públicas - VII EPEA - Julho de 2013

Um dado que chama atenção, no quadro apresentado, é a preocupação predominante com a questão do licenciamento ambiental, notadamente com relação à exploração do petróleo e do gás. Aproximadamente, um terço dos trabalhos apresentados $(28,5 \%)$ tratam dessa temática, ressaltando a necessidade do controle social (Tr0030-1), o desafio da educação ambiental crítica nesse contexto (Tr0044-1), os projetos de educação ambiental desenvolvidos (Tr0071-1; Tr0078-1), as disputas de ideias e as influências nos processos educativos (Tr0210-1) enfim, os limites e as possibilidades da educação ambiental (Tr0108-1) no processo de licenciamento. A investigação sobre formas de desenvolvimento de uma dada política pública, seja por meio de algum tipo de programa, projeto ou a socialização da política em conselhos também foram temas contemplados em trabalhos apresentados no GDP. A temática referente às tendências das teses e dissertações sobre áreas protegidas no Brasil também está presente. Além disso, encontramos investigação sobre princípios ambientais numa determinada instituição, políticas públicas de Educação Ambiental na escola, na organização do currículo ou na organização da juventude em geral. Ainda, a perspectiva crítica e a educação ambiental política são explicitadas em temas dos trabalhos apresentados no GDP.

Além dos temas presentes nos trabalhos apresentados no GDP, destacamos, no quadro II, os objetivos dos trabalhos e a problemática expressa neles:

\section{OBJETIVOS/PROBLEMÁTICA DOS TRABALHOS \\ (...) discutir a representação dos princípios ambientais da informação e da participação no âmbito da educação ambiental.}

ID.$^{3}$

(...) compreender, enquanto mediação essencial, o contexto que conforma o controle social na formação sócio-histórica brasileira, a fim de elencar elementos que subsidiassem a reflexão acerca dos instrumentos de controle social no licenciamento ambiental com ênfase na estratégia conselhista.

(...) analisou os desafios para o desenvolvimento de Programas de Educação Ambiental (PEAs), em um marco político institucional crítico e transformador, no sentido de constituir uma política pública no âmbito do licenciamento ambiental federal.

(...) compreender como o ideário ambiental é articulado nos processos educacionais promovidos pelo Estado Brasileiro e como um programa de educação ambiental, promovido por este Estado, insere-se na dinâmica de luta de classes no campo.

(...) buscou identificar, através de um diagnóstico socioambiental do campus de Porto Alegre da Pontifícia Universidade Católica do Rio Grande do Sul (PUCRS), como ocorre a internalização de práticas e políticas de sustentabilidade e de acessibilidade nessa universidade.

\footnotetext{
${ }^{3}$ Os trabalhos são identificados conforme a inscrição no VII EPEA (2013) e publicação dos Anais do mesmo evento.
} 
(...) analisar a implantação da Agenda 21 nas escolas do estado de São Paulo, protagonizada pelas duas diferentes instâncias: a federal e a estadual paulista. (...) analisar os projetos de educação ambiental implementados no licenciamento off-shore de petróleo na Bacia de Campos (...) e os instrumentos jurídicos norteadores dessa política.

(...) discutir, a partir da entrada de projetos de educação ambiental de organizações privadas nas escolas públicas, suas implicações para as estratégias empresariais e para a comunidade escolar.

(...) investigar como pescadores e marisqueiras do Recôncavo Baiano se apropriam daquele programa (Projetos de educação ambiental para pescadores artesanais - Licenciamento de Petróleo e Gás) e que resultados podem ser observados.

(...) analisar, a partir da ótica da Educação Ambiental Crítica, e utilizando a dialética como metodologia, os princípios da Política Nacional de Assistência Técnica e Extensão Rural para a Agricultura Familiar e Reforma Agrária (PNATER).

(...) escolhemos o estudo da percepção ambiental num esforço de compreender o que define a maneira como o ser humano se relaciona com seu entorno e o que concebe como qualidade ambiental e qualidade de vida. (...) procuramos dar ênfase às relações de percepção em relação à água (...).

(...) análise acerca dos limites e possibilidades da educação ambiental no âmbito do licenciamento ambiental ligado, especialmente, aos empreendimentos marítimos petrolíferos.

(...) reflete sobre discursos contra-hegemônicos proferidos na Rio+20 e sua relação com a proposta do espaço oficial de participação da sociedade nessa conferência.

Considerando o contexto das pesquisas acadêmicas sobre Educação Ambiental (EA) em Áreas Protegidas, realizou-se uma pesquisa bibliográfica por meio da análise das informações institucionais e dos resumos das dissertações e teses produzidas sobre a temática, a fim de se obter um panorama da produção acadêmica nesse campo específico.

(...) análise do contexto no qual surgiu a política pública de educação ambiental COM-VIDA, bem como apresentar os princípios teóricos e aspectos metodológicos que a regem.

(...) relacionar a análise dos limites e possibilidades da política das Comissões Interinstitucionais Estaduais de EA (CIEA) e do Grupo interdisciplinar de EA (GIEA), com o processo de "onguização" à partir da entrada do Sindicato de Profissionais da Educação - RJ - (SEPE) no Conselho de Educação Ambiental do Estado do RJ.

(...) reflexão sobre o status das mulheres atuantes na cadeia produtiva da pesca, tendo como cenário as comunidades pesqueiras artesanais do Rio Grande/RS e de São José do Norte/RS.

(...) reflexões a partir do quadro teórico da educação ambiental crítica, sobre o processo da Conferência Nacional Infanto-Juvenil pelo Meio Ambiente (CNIJMA) e o projeto político de Escolas Sustentáveis.

(...) analisou o conteúdo dos documentos curriculares nacionais do Ensino Médio - Diretrizes Curriculares Nacionais (1998 e 2012) e Parâmetros Curriculares Nacionais (1999) - em relação ao desenvolvimento da temática ambiental.

(i) analisar as diferentes compreensões sobre questões conceituais que sustentam os pressupostos da Educação no Processo de Gestão Ambiental Pública, presentes no discurso dos representantes das instituições responsáveis pela condução dos processos educativos no âmbito do licenciamento de petróleo e gás; (ii) verificar em que medida essas diferentes compreensões conceituais, no cerne da estrutura interinstitucional do licenciamento ambiental, podem se aproximar ou se afastar dos pressupostos da Educação no Processo de Gestão Ambiental Pública; e (iii) averiguar se, por conta da posição na estrutura social, as instituições, a partir de seus agentes sociais, expressam esses conceitos de forma diferenciada entre elas.

$\operatorname{Tr} 0069-1$

$\operatorname{Tr} 0071-1$

$\operatorname{Tr} 0073-1$

Tr0078-1

\author{
$\operatorname{Tr} 0087-1$
}

$\operatorname{Tr} 0099-1$

$\operatorname{Tr} 0108-1$

$\operatorname{Tr} 0112-1$

$\operatorname{Tr} 0126-1$

Tr0138-1

\author{
Tro160-1
}

$\mathrm{T}$

$\operatorname{Tr} 0186-1$

Tr0187-1

Tr0197-1

\begin{tabular}{|l|l|} 
& $\operatorname{Tr} 0197-1$ \\
\hline es & \\
ar & \\
ar & $\operatorname{Tr} 0210-1$ \\
\hline de & \\
\hline
\end{tabular}


(...) esclarecer os caminhos da educação ambiental nos contextos sociais internacionais como pretextos para a criação de determinadas políticas públicas Tr0210-2 nas áreas de educação e meio ambiente.

QUADRO II - Objetivos e a problemática dos trabalhos apresentados no GDP de Pesquisa em Educação Ambiental e Políticas Públicas - VII EPEA, Julho de 2013:

Fonte: Trabalhos apresentados no GDP Pesquisa em Educação Ambiental e Políticas Públicas - VII EPEA - Julho de 2013.

Analisar, compreender, refletir, discutir, investigar, esclarecer, pesquisar, verificar, averiguar, relacionar são os verbos mais comumente usados para expressar os objetivos dos pesquisadores nos trabalhos do GDP sobre Pesquisa em Educação Ambiental e Políticas Públicas. Tais verbos, embora não sejam os únicos elementos suficientes para tal, denotam a natureza dos trabalhos apresentados enquanto trabalhos de pesquisa.

O uso dos verbos acima mencionados e a relação que é expressa pelos pesquisadores com a temática tratada anteriormente no âmbito deste texto (QUADRO I) nos indicam a abrangência dos objetivos dos trabalhos apresentados no GDP (QUADRO II).

No que se refere à problemática investigada pelos pesquisadores cujos trabalhos foram apresentados no GDP de Pesquisa em Educação Ambiental e Políticas Públicas, expressa em meio aos objetivos, constatam-se questões de ordem mais restrita e outras de ordem mais ampla, geral; contudo, há que ressaltar, como um dado importante e necessário no processo de investigação sobre política pública e educação ambiental, a preocupação dos pesquisadores em estabelecer os nexos necessários entre as questões tratadas. Ou seja, relacionar questões restritas com questões mais amplas ou vice-versa. Assim, apenas para ilustrar, identificamos, por um lado, trabalhos cuja problemática dizia respeito a uma instituição específica, como no caso, uma universidade (PUCRG), porém com a preocupação de investigar "como ocorre a internalização de práticas e políticas de sustentabilidade e de acessibilidade" (Tr0067-1). Ou ainda, a preocupação de investigar "como pescadores e marisqueiras do Recôncavo Baiano se apropriam" de projetos de educação ambiental no processo de licenciamento de petróleo e gás (Tr0078-1) Por outro lado, identificamos trabalho cuja problemática diz respeito à compreensão sobre "como o ideário ambiental é articulado nos processos educacionais promovidos pelo Estado Brasileiro e como um programa de educação ambiental promovido por este estado é inserido na dinâmica de luta de classes no campo" (Tr0063-00). Em outro trabalho os pesquisadores buscam "esclarecer os caminhos da educação ambiental nos contextos sociais internacionais como pretextos para a criação de determinadas políticas públicas" (Tr0210-1).

Completando esses dados, apresentamos, sucintamente, algumas informações que consideramos relevantes sobre o referencial teórico-metodológico bem como sobre os tipos de pesquisa e os procedimentos mais frequentes adotados.

No que diz respeito ao referencial teórico-metodológico explicitamente indicado nos trabalhos apresentados no GDP de Pesquisa em Educação Ambiental e Políticas Públicas, chama a atenção a predominância do materialismo histórico-dialético. Tal referencial está explicitamente presente em 28,57\% dos trabalhos (Tr0044-1; Tr0063-1; Tr0073-1; Tr0160-1; Tr0210-1; Tr0210-2), sendo que, na maioria deles, (em 23,80\%) tal indicação é feita explicitamente a Antonio Gramsci (Tr0044-1, Tr0063-1; Tr0073-1; Tr0160-1; Tr0210-2) buscando nele a fundamentação de alguns conceitos tais como Estado Ampliado, sociabilidade, hegemonia, conformismo, partido e escola 
desinteressada. A perspectiva da educação ambiental crítica também é explicitada nos trabalhos apresentados com a fundamentação no materialismo histórico-dialético e, por vezes, aparece também a denominação de crítica emancipatória (Tr0073-1). Um trabalho se fundamenta expressamente na Ecologia Política, a qual assume que:

[...] as relações entre os grupos sociais são assimétricas, ou seja, que há grupos dominantes e dominados, e que isto determina a forma como tais grupos irão se apropriar dos recursos naturais, ou impedir os outros de seu uso, a Ecologia Política prioriza o aspecto socioeconômico na bandeira de defesa do meio ambiente (ALIMONDA, 2002) (Tr0078-1).

Vale lembrar que a obra referida anteriormente é publicada pelo Conselho Latinoamericano de Ciências Sociais (CLASCO).

No que se refere aos tipos de pesquisa (GODOY, 1995), constata-se a predominância da pesquisa documental ou bibliográfica, realizada em documentos institucionais, arquivos, teses, dissertações etc. Tal tipo de pesquisa aparece em 52,38\% do total dos trabalhos apresentados no GDP (Tr0027-1; Tr0063-1; Tr0067-1; Tr0069-1; Tr0078-1; Tr0108-1; Tr0126-1; Tr0138-1; Tr0160-1; Tr0186-1; Tr0197-1).

Outro tipo de pesquisa que chama a atenção é o Estudo de Caso. Ele está presente em 19,04\% dos trabalhos apresentados (Tr0044-1; Tr0073-1; Tr0078-1; Tr0160-1).

Nos procedimentos de pesquisa, a entrevista é usada com certa frequência $(38,09 \%)$ nos trabalhos apresentados no GDP (Tr0044-1; Tr0063-1; Tr0067-1; Tr00711; Tr0078-1; Tr0099-1; Tr0160-1; Tr0210-11); alguns deles, o equivalente a 19,04\% do total, explicitam a modalidade de entrevista semiestruturada (Tr0044-1; Tr0099-1; Tr0160-1; Tr0210-1). Por vezes, (em 19,04\% dos trabalhos) a entrevista é um procedimento que completa a pesquisa documental ((Tr0063-1; Tr0067-1; Tr0078-1; Tr0160-1). Isto também ocorre, embora com menor frequência, em relação à aplicação de questionário, além da entrevista (Tr0044-1). A análise de conteúdo, tendo Laurence Bardin como referência, é explicitamente citada em 14,28\% dos trabalhos apresentados (Tr. 0078-1; Tr0197-1; Tr0210-1).

Durante a realização das discussões do GDP de Pesquisa em Educação Ambiental e Políticas Públicas, após a exposição feita inicialmente pelos pesquisadores, que procuramos no âmbito deste artigo registrar por meio dos dados presentes nos quadros I e II, e considerando a riqueza de elementos para possíveis aprofundamentos, porém, em razão do tempo disponível optou-se, naquela ocasião, pela discussão de dois deles, considerados fundamentais:

1. Que elementos são indicativos de entendimentos dos autores sobre o que é educação ambiental?

2. Que elementos são indicativos de entendimentos dos mesmos autores sobre o que é Política Pública?

Para nortear as discussões sobre essas duas questões, além da apresentação dos trabalhos, feita pelos autores presentes no GDP, foram também usados excertos de todos os trabalhos inscritos, recolhidos pelo coordenador do GDP, contemplando o foco de discussão proposto. Além disso, foram recuperados e inseridos na discussão os oito temas propostos durante a realização do GDP no VI EPEA, em 2011, a saber:

1. Os conceitos de Estado e sociedade civil nas políticas públicas de educação ambiental. 
2. Limites e estratégias para que as políticas públicas possam se constituir como políticas de Estado, políticas estruturantes, mais densas e menos instáveis.

3. As tensões indivíduo-instituição na formulação das políticas públicas.

4. O lugar das políticas públicas em educação ambiental no Estado (o quão estratégicas elas são, se são marginais... que condições têm para sair desse lugar mais marginalizado?).

5. A relação das políticas públicas de educação ambiental com outras políticas públicas, destacadamente, as de educação (reiteradas várias vezes), mas também as demais políticas sociais, de saneamento, de saúde etc.

6. Estudo das condições objetivas das políticas públicas de educação ambiental (como se constroem as equipes, orçamentos, quais são as condições de se desenvolver políticas).

7. Mais estudos de caso (pontuais e mais abrangentes municipais, estaduais e federais) da materialização das políticas públicas de educação ambiental com vistas a traçar diagnósticos e mapeamentos.

8. Os diferentes interesses da sociedade civil em jogo na definição das políticas de educação ambiental (relação das políticas de EA com as demandas dos movimentos sociais, sobretudo, ligados à educação).

Dentro da dinâmica e movimento da discussão empreendida pelo GDP de Pesquisa em Educação Ambiental e Políticas Públicas, há que se ressaltar, como um dado de significativa importância, o fato de que parte considerável dos trabalhos apresentados no VII EPEA foi desenvolvida reflexionando as perspectivas de pesquisa indicadas no VI EPEA, já relembradas neste artigo.

Para a discussão do foco indicado, e conforme acordado no GDP, foram constituídos dois grupos de trabalho a partir da negociação dos interesses de cada participante. Da discussão empreendida foram destacados os seguintes apontamentos sobre os dois focos propostos ${ }^{4}$ :

1. Entendimentos sobre Educação Ambiental presentes nos trabalhos apresentados no GDP de Pesquisa em Educação Ambiental e Políticas Públicas - VII EPEA (2013):

1.1. O campo da educação ambiental é um espaço em disputa.

1.2. A educação ambiental deve ocorrer a partir do entendimento da realidade social vivida.

1.3. A educação ambiental é uma ação política de instrumentalização dos grupos sociais em situação de vulnerabilidade socioambiental para a transformação social e reversão das assimetrias.

\footnotetext{
4 Tais apontamentos tiveram a colaboração de Mônica Armond Serrão e Inny Bello Accioly, às quais agradecemos pela colaboração. Da mesma forma, colaboraram com apontamentos sobre o processo de discussão ocorrido no primeiro dia do evento, Rosa Maria Tóro Tonissi e Maryane Saisse, às quais também somos gratos.
} 
1.4. A educação ambiental requer uma intencionalidade, um posicionamento político claro para que se alcance o projeto político defendido.

1.5. As ações de educação ambiental devem considerar o conceito de público a partir de uma dimensão universalista.

1.6. A educação ambiental deve buscar alcançar objetivos coerentes com a proposta de uma efetiva emancipação humana.

1.7. A educação ambiental deve estar voltada para a construção da participação e do controle social das políticas públicas.

1.8. A educação ambiental não deve ser apartada do campo da educação.

1.9. Finalmente, registrou-se que o conceito de educação ambiental apareceu, ainda que em poucos trabalhos, numa perspectiva comportamentalista, preservacionista e dicotômica, voltada para a sensibilização dos educandos, defendendo, contraditoriamente, a relevância da educação ambiental crítica.

2. Quanto ao segundo foco da discussão empreendida nos grupos de trabalho, referente aos entendimentos de Políticas Públicas, ressaltam-se os seguintes aspectos:

2.1. Entendimentos distintos sobre políticas públicas, bem como da forma de participação nas mesmas. Tais entendimentos estão diretamente vinculados à compreensão da natureza e do papel do estado. Assim, cabe destacar:

2.1.1. O estado não é uma instituição neutra, conforme constatado em alguns trabalhos apresentados.

2.1.2. É importante compreender, segundo outros trabalhos, a natureza do estado no contexto da sociedade capitalista e a influência da classe dominante no processo de formulação das políticas públicas.

2.1.3. Nesse contexto, há trabalhos que consideram que o estado está a serviço do privado, a serviço da burguesia. Há subordinação do estado às empresas privadas. No que se refere à presença do setor privado nas políticas públicas, alguns trabalhos trazem, também, a crítica às parcerias público-privadas.

2.1.4. O estado aparece muitas vezes, em trabalhos apresentados, como mediador de conflitos. Em alguns trabalhos considera-se o estado que preserva a ordem estabelecida e, em outros, principalmente quando se trata do financiamento das políticas públicas, salientase a responsabilidade do estado, reforçando a ideia do estado mediador.

2.1.5. Em trabalhos apresentados no GDP a disputa é considerada um elemento importante na compreensão do estado. As contradições internas ao estado são enfatizadas em contraposição à visão ingênua de estado enquanto entidade que cuida do bem comum.

2.2. Há trabalhos onde a questão das políticas públicas esta relacionada às garantias de direitos e, em outros, à redistribuição de benefícios:

2.2.1. Garantias de direitos fundamentais à vida (alimentação, saúde etc.) e outros de outra ordem (liberdade, por exemplo). 
2.2.2. Redistribuição dos benefícios sociais com vistas à diminuição das desigualdades estruturais.

2.3. Outra ideia importante, e que chama a atenção na discussão sobre os trabalhos apresentados no GDP, vincula-se à necessidade de participação e de controle social das políticas públicas.

2.3.1. A participação está presente nos trabalhos apresentados no GDP, tanto no que se refere aos indivíduos, aos movimentos sociais ou, ainda, aos movimentos populares ou sindicais.

2.3.2. Em alguns trabalhos os espaços de participação nas políticas públicas são entendidos como espaços de disputas. A ideia de consenso e de parceria, apesar de em menos quantidade, também aparece em trabalhos apresentados. Chama a atenção, em alguns deles, a crítica a respeito da proliferação das ONGs nas políticas públicas, visando, muitas vezes, a defesa de interesses privados.

2.3.3. Ainda sobre a participação, a questão da necessidade da assimetria na constituição das políticas públicas e no uso de recursos é também uma ideia presente e valorizada.

Tendo discutido os trabalhos inscritos no GDP Pesquisa em Educação Ambiental e Políticas Públicas, com foco nos elementos indicativos do entendimento sobre educação ambiental e sobre políticas públicas presentes neles, buscou-se, ainda, indicar temas que pudessem contribuir para o avanço das pesquisas sobre Educação Ambiental e Políticas Públicas. Os pesquisadores presentes na discussão do GDP consideraram importante reforçar os oito temas definidos em discussão ocorrida no VI EPEA (indicados anteriormente neste artigo) e, além deles, acrescentar outros três temas. Assim, além dos oito, foram acrescentados os seguintes:

9 - Pesquisas enfocando os aspectos ambientais e educacionais, em especial aquelas que avaliam os resultados e/ou consequências das políticas públicas quanto a tais aspectos.

10 - Análise dos resultados das políticas públicas (considerando a carência na divulgação dos resultados das políticas públicas pelo próprio Estado).

11 - Buscar explicitar elementos resultantes da investigação que indiquem perspectivas de uma efetiva emancipação humana, evitando, com isto, a desilusão e o desânimo (tanto para o pesquisador quanto para os sujeitos das pesquisas desenvolvidas).

\section{Considerações Finais}

Em se tratando de perspectivas para o GDP de Pesquisa em Educação Ambiental e Políticas públicas, enquanto campo emergente de pesquisa, reforçamos o que já fora constatado por Ferraro (2013, p. 143), por ocasião do VI EPEA, ao afirmar que esse GDP demonstra uma "vitalidade e uma pertinência social e política que justifica sua continuidade nos próximos EPEAS".

Esperamos que os elementos trazidos no âmbito deste artigo - de registros, memórias e possibilidades de análises - possam contribuir para a sistematização de novas pesquisas e para a consolidação da temática sobre Educação Ambiental e Políticas Públicas no campo da pesquisa em Educação Ambiental, em permanente construção. 


\section{Referências}

CARVALHO, I.C. de M; SCHMIDT L. S. A pesquisa em Educação Ambiental: uma análise dos trabalhos apresentados na ANPED, ANPPAS e EPEA de 2001 a 2006. Pesquisa em Educação Ambiental, Rio Claro, v. 3, n. 2, p.147-174, Jul./Dez. 2008. Disponível em: <http://www.periodicos.rc.biblioteca.unesp.br/index.php/pesquisa/article/view/6173/4528 >. Acesso em: 30 jun. 2014.

CARVALHO, I. C. de M.; FARIAS, C. R. de O. Um balanço da produção científica em educação ambiental de 2001 a 2009 (ANPED, ANPPAS E EPEA). Revista Brasileira de Educação, Rio de Janeiro. RJ. v. 16, n. 46. p.119-134; 266-267, Jan./Abr. 2011. Disponível em: <http://www.scielo.br/pdf/rbedu/v16n46/v16n46a07.pdf>. Acesso em: 30 jun. 2014.

CAVAlaRI, R. M. F.; SANTANA, L. C.; CARVAlHO, L. M. Concepções de educação e educação ambiental nos trabalhos do I EPEA. Pesquisa em Educação Ambiental, Rio Claro, v.1, n.1, p.141-173, Jan./ Jun. $2006 . \quad$ Disponível em: <http://www.periodicos.rc.biblioteca.unesp.br/index.php/pesquisa/article/view/6123/4488>. Acesso em: 30 jun. 2014.

FERRARO JR., L. A. Dialogar e digladiar: entre a conflagração e a constituição do campo da pesquisa sobre políticas públicas de educação ambiental. Pesquisa em Educação Ambiental, Rio Claro, v. 7, n. 2, p.133-145, Jul./Dez. 2012. Disponível em: <http://www.periodicos.rc.biblioteca.unesp.br/index.php/pesquisa/article/view/6866/4969>. Acesso em: 30 jun. 2014.

GELINSKI, C. R. O. G; SEIBEL, E. J. Formulação de Políticas Públicas: questões metodológicas relevantes. Revista de Ciências Humanas, Florianópolis, EDUFSC. v. 42, n. 1. p. 227-240. Abr./Out. 2008.

GODOY, A. S. Pesquisa Qualitativa: tipos fundamentais. Revista de Administração de Empresas, São Paulo. v.35, n.3, p. 20-29, Mai./Jun. 1995.

GUIMARÃES, M.; OLABARRIAGA, N.; TONSO, S. A pesquisa em políticas públicas e Educação Ambiental. Pesquisa em Educação Ambiental, Rio Claro, v.4, n.2, p.215-227, Jul./Dez. 2009.2 Disponível em: <http://www.periodicos.rc.biblioteca.unesp.br/index.php/pesquisa/article/view/6202/4550>. Acesso em: 30 jun. 2014.

JUNTA, V. da S.; SANTANA, L. C. Concepções de educação ambiental e suas abordagens políticas: análise de trabalhos dos Encontros de Pesquisa em Educação Ambiental (I,II e III EPEAs). Pesquisa em Educação Ambiental, Rio Claro, v. 6, n.1. p.47-65, Jan./Jun. 2011. Disponível em:

<http://www.periodicos.rc.biblioteca.unesp.br/index.php/pesquisa/article/view/6227/4573>. Acesso em: 30 jun. 2014.

KAWASAKI, C. S. et. al. O perfil do pesquisador em educação ambiental: elementos para um estudo sobre a constituição de um campo de pesquisa em educação ambiental. Pesquisa em Educação Ambiental, Rio Claro, v.1, n.1, p.111-140, Jan./Jun. 2006. Disponível em: <http://www.periodicos.rc.biblioteca.unesp.br/index.php/pesquisa/article/view/6118/4487>. Acesso em: 30 jun. 2014. 
KAWASAKI, C. S. et. al. A pesquisa em educação ambiental nos EPEAs (2001 - 2007): natureza dos trabalhos, contextos educacionais e focos temáticos. Pesquisa em Educação Ambiental, Rio Claro, v. 4, n.2, p.147 - 163, Jul./Dez. 2009. Disponível em: <http://www.periodicos.rc.biblioteca.unesp.br/index.php/pesquisa/article/view/6197/4545>. Acesso em: 30 jun. 2014.

LAYRARGUES, P. P. A conjuntura da institucionalização da Política Nacional de Educação Ambiental. In: OLAM: Ciência \& Tecnologia, Rio Claro, ano II. v. 2. n.1, p. 1-14, Abr. 2002.

LIMA, G. F. da C. A institucionalização das políticas e da gestão ambiental no Brasil: avanços, obstáculos e contradições. Desenvolvimento e Meio Ambiente, Curitiba, v.23, p.121-132, Jan./Jun. 2011a.

LIMA, G. F. da C. Educação Ambiental no Brasil: formação, identidades e desafios. Campinas: Papirus, 2011b (Coleção Papirus Educação).

MARQUES, E.; FARIA, C. A. P. de. A Política Pública como Campo Multidisciplinar. Rio de Janeiro: Fiocruz / São Paulo: Editora UNESP, 2013.

RINK, J.; MEGID NETO, J. Tendências dos artigos apresentados nos Encontros de Pesquisa em Educação Ambiental (EPEA). Educação em revista, Belo Horizonte, v.25, n.3, p. 235-263, Set./Dez. 2009.

SORRENTINO, M.; TRAJBER, R. Políticas de Educação Ambiental do Órgão Gestor. In: BRASIL. Vamos cuidar do Brasil: conceitos e práticas em educação ambiental na escola. Brasília: UNESCO, 2007. p.13-21.

SOUZA, C. Estado da arte da Pesquisa em Políticas Públicas, In: HOCHMAN, G.; ARRETCHE, M.; MARQUES, E. (Orgs.) Políticas Públicas no Brasil. Rio de Janeiro: FIOCRUZ, 2007. p. 65-86.

TAMAIO, I. A Política de Educação Ambiental. In: Educação Ambiental no Brasil - Salto para o futuro, Brasília: Secretaria de Educação à Distância/ MEC, Ano XVIII, boletim 01, p. 21-29, Mar. 2008.

Artigo submetido em 20/04/2014

Artigo aprovado em 30/06/2014 